\title{
ORBITAL LYMPHOMAS AND CASTLEMAN'S DISEASE
}

\author{
M. P. SNEAD ${ }^{1}$, J. N. JAMES ${ }^{1}$, D. R. J. SNEAD ${ }^{2}$, D. K. ROBSON ${ }^{2}$ and S. N. M. RIZK ${ }^{1 *}$ \\ Nottingham
}

\begin{abstract}
SUMMARY
A series of 100 consecutive orbitotomies for tumour was assessed. Lymphoid infiltrations contributed $27 \%$ and malignant non-Hodgkin lymphoma was the commonest primary malignant orbital tumour in this series. The clinical and histological features of the first histologically proven case of primary orbital Castleman's disease are reported, as are the results of a study of 27 patients with pure orbital lymphoid infiltrations. The natural history of conjunctival lymphomas differs significantly from that of pure orbital lymphomas and for this reason no conjunctival lymphomas were considered in this series (which therefore contrasts with some previous reports). Histological examination with fresh unfixed tissue available for immunohistochemical staining enhances the diagnostic accuracy of these varied underlying diseases. More than one biopsy may be required before the diagnosis is established. These are significant factors given the differing lines of management for each disorder.
\end{abstract}

Lymphoid infiltrations of the orbit have been described as accounting for $10-15 \%$ of orbital tumours.' A series of 100 consecutive orbitotomies for tumour was studied and those due to lymphoid infiltrations $(n=27)$ reassessed. No conjunctival lymphoid infiltrations were considered in this series. One patient who presented as a case of typical orbital lymphoma was found to have Castleman's disease, which has not previously been described as presenting in this manner.

Castleman's disease was first described by Benjamin Castleman in $1954 .{ }^{2}$ It is a pathological entity of unknown aetiology, which may explain the wide variety of names used to describe it in the literature: lymph node hyperplasia, ${ }^{2,3}$ lymph node hamartoma,${ }^{4}$ tumour-like proliferation of lymphoid tissue, ${ }^{5}$ follicular lymphoreticuloma ${ }^{6}$ and angiomatous lymphoid hyperplasia. ${ }^{7}$ The hyaline vascular variety of Castleman's disease, which presents as an isolated compressive lesion, has been described in a number of anatomical sites. It is most commonly found as a solitary mass in the mediastinum (70\%), abdomen, neck

From: 'Orbital Clinic and ${ }^{2}$ Department of Histopathology, University Hospital, Nottingham NG7 2UH, UK. *Director Orbital Services.

Correspondence to: M. P. Snead, FRCS, Department of Ophthalmology, Addenbrooke's Hospital, Hills Road, Cambridge CB2 2QQ, UK. and axilla; there is a single proven report of intracranial involvement. ${ }^{8}$ Gittinger ${ }^{9}$ has described a case of Castleman's disease of the thorax with later CT evidence of posterior scleral thickening and a parietal intracranial lesion. No conclusive histological findings were obtained from the ocular or cranial lesions, which resolved with radiotherapy.

\section{METHOD}

Twenty-seven patients with orbital lymphoid infiltrations were found in a series of 100 consecutive orbitotomies performed because of suspected neoplasm. Twenty patients were reassessed clinically. The case records for the 7 patients who had died were reviewed and the cause of death ascertained. The histological and immunohistochemical findings were reviewed in all cases. The patients were examined clinically and in all but one case (who declined the examination) by CT or MRI. The diagnosis was established in all cases by biopsy.

Ophthalmic assessment paid particular attention to the duration of symptoms together with any pain or inflammatory response. Any treatment the patient was already receiving was documented. Visual acuities, degree of proptosis, extraocular motility and visual fields were recorded in addition to the results of a general anterior and posterior segment ophthalmic examination. Photographs were taken and patients were screened for other evidence of systemic lymphoma, notably lymphadenopathy, hepatosplenomegaly, and cutaneous or haematological abnormality. Patients with histologically proven lymphoma were staged according to the Ann Arbor classification. $^{10}$

\section{CLINICAL RESULTS}

The causes of the orbital tumours are given in Table I. The 27 cases of lymphoid infiltration were classified according to biopsy as shown in Table II.

There were 13 female and 14 male patients. The mean age at diagnosis was 59.6 years. If the 2 cases of histiocytosis $\mathrm{X}$ are excluded (ages 7 and 9 years) the mean age at diagnosis was 63.7 years (range 24-96 years). Two patients were already receiving systemic steroid therapy prior to their referral and biopsy. In one of these the biopsy 
Table I. Results of 100 consecutive orbitotomies for tumour

\begin{tabular}{lc}
\hline Diagnosis & $\begin{array}{c}\text { No. of } \\
\text { patients }\end{array}$ \\
\hline Non-Hodgkin lymphoma & 17 \\
Metastatic tumour & 12 \\
Haemangioma & 8 \\
Meningioma & 7 \\
Reactive lymphoid & 6 \\
Neurofibroma & 5 \\
Rhabdomyosarcoma & 5 \\
Lacrimal carcinoma & 4 \\
Dermoid & 4 \\
Schwannoma & 3 \\
Orbital varix & 3 \\
Pleomorphic adenoma & 3 \\
Others & 20 \\
\hline
\end{tabular}

${ }^{a}$ One or two each.

was inconclusive; the other had received steroid for 15 years and biopsy confirmed malignant non-Hodgkin lymphoma which underwent complete remission with radiotherapy, the patient remaining disease-free 4 years later.

Two other patients who were not receiving steroid required a subsequent biopsy before the diagnosis of malignant non-Hodgkin lymphoma was confirmed. Of the 17 patients with biopsy-proven non-Hodgkin lymphoma, most had a more prolonged duration of clinical symptoms prior to presentation (mean 22 months, range 1-120 months) with a pain-free infiltrate, although 4/17 (23.5\%) did have associated pain.

Most of the patients in the reactive/atypical group presented with a more rapid onset of symptoms (mean 4 months, range 1-12 months). Only 1 of the 6 was pain-free.

Both the patients with histiocytosis X presented with a 2-3 month history of progressive pain-free proptosis.

\section{Orbital Non-Hodgkin Lymphoma}

In $15 / 17$ patients with malignant non-Hodgkin lymphoma the presenting primary pathology was orbital disease. In the remaining 2 patients the orbital involvement was a secondary finding at a mean time of 18 months after initial

Table II. Orbital lymphoid infiltrations

\begin{tabular}{|c|c|c|c|c|}
\hline Diagnosis & No. & Stage & $\begin{array}{c}\text { Survival } \\
\text { (Mean follow- } \\
\text { up, months) }\end{array}$ & Treatment \\
\hline High-grade & 4 & 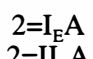 & $\begin{array}{c}4 \\
(1250\end{array}$ & $\mathrm{I}_{\mathrm{E}} \mathrm{A}=\mathrm{RT}$ \\
\hline $\begin{array}{l}\text { NHL } \\
\text { Low-grade }\end{array}$ & 13 & $\begin{array}{l}Z=\mathrm{H}_{\mathrm{E}} \mathrm{A} \\
7=\mathrm{I}_{\mathrm{F}} \mathrm{A}\end{array}$ & $\begin{array}{c}\text { (12.5 mo.) } \\
8 \text { alive }\end{array}$ & $\begin{aligned} \mathrm{II}_{\mathrm{E}} \mathrm{A}=\mathrm{CT} \\
\mathrm{J}_{\mathrm{C}} \mathrm{A}=\mathrm{RT}\end{aligned}$ \\
\hline NHL & & $\begin{aligned} 4 & =\mathrm{II}_{\mathrm{E}} \mathrm{A} \\
2 & =\mathrm{IV}\end{aligned}$ & $\begin{array}{c}3 \text { deceased (CU) } \\
2 \text { deceased (CR) } \\
\text { (52.1 mo.) }\end{array}$ & $\begin{array}{l}\mathrm{II}_{\mathrm{E}} \mathrm{A}=\mathrm{RT} / \mathrm{CT} \\
\mathrm{IV}=\mathrm{RT}+\mathrm{CT}\end{array}$ \\
\hline $\begin{array}{l}\text { Reactive/ } \\
\text { atypical }\end{array}$ & 6 & $6=I_{E} A$ & $\begin{array}{c}4 \\
2 \text { deceased }(\mathrm{CU})\end{array}$ & $\begin{array}{c}\text { 4=steroid } \\
2=\text { nil }\end{array}$ \\
\hline Plasmacytoma & 1 & MM & $\begin{array}{c}1 \\
(19 \text { mo.) }\end{array}$ & $\mathrm{CT}$ \\
\hline Histiocytosis X & 2 & $2=I_{E} A$ & $\begin{array}{c}2 \\
(9 \mathrm{mo} .)\end{array}$ & $\begin{array}{c}1=\mathrm{CT} \\
1=\text { excised }\end{array}$ \\
\hline Castleman's & 1 & $\mathrm{I}_{\mathrm{E}} \mathrm{A}$ & $\begin{array}{c}1 \\
(60 \mathrm{mo} .)\end{array}$ & Excised \\
\hline
\end{tabular}

NHL, non-Hodgkin lymphoma; MM, multiple myeloma; CR, cause related; CU, cause unrelated; $\mathrm{CT}$, chemotherapy; RT, radiotherapy. diagnosis (range 12-24 months). Of the patients presenting with orbital disease 9 were stage $\mathrm{I}_{\mathrm{E}} \mathrm{A}, 4$ were stage $\mathrm{II}_{\mathrm{E}} \mathrm{A}$ and 2 were stage IV. Both patients presenting with orbital disease as a secondary feature were stage $\mathrm{II}_{E} \mathrm{~A}$. Five patients have died in this (malignant non-Hodgkin lymphoma) group; 2 deaths were cause related (both stage IV), while 3 died from unrelated causes.

\section{Castleman's Disease}

A 26-year-old Caucasian woman presented with a 4-5 year history of progressive painless swelling involving the right upper eyelid. This caused a downward displacement of the globe. She had no diplopia and no constitutional disturbance and in particular she had no sweating, fever, malaise or raised erythrocyte sedimentation rate. She had had one normal pregnancy and a history of a resolved right Bell's palsy at the age of 7 years. Apart from the progesterone contraceptive pill she was receiving no other medication. There was no family history of illness. She did not smoke. Results of systemic examination and investigation were normal.

Ophthalmic examination revealed a firm palpaple mass deep to the lateral aspect of the right upper eyelid which was not tender. The globe was displaced inferiorly with $3 \mathrm{~mm}$ proptosis measured using a Hertel exophthalmometer. The visual acuities were $6 / 5$ for the right eye and $6 / 5$ for the left. The eye movements were full and there was no visual field defect. Fundoscopy was normal.

A CT scan was carried out in both axial and coronal planes and demonstrated a well-defined enhancing mass in the right lacrimal fossa extending posteriorly half-way to the apex of the orbit, displacing the muscle cone medially. There were no associated bony changes (Fig. 1). Excision biopsy was performed via a lateral orbitotomy and the patient retains a visual acuity of $6 / 5$ for the right eye and $6 / 5$ for the left with full ocular movements and no evidence of recurrence on CT scan 5 years following surgery.

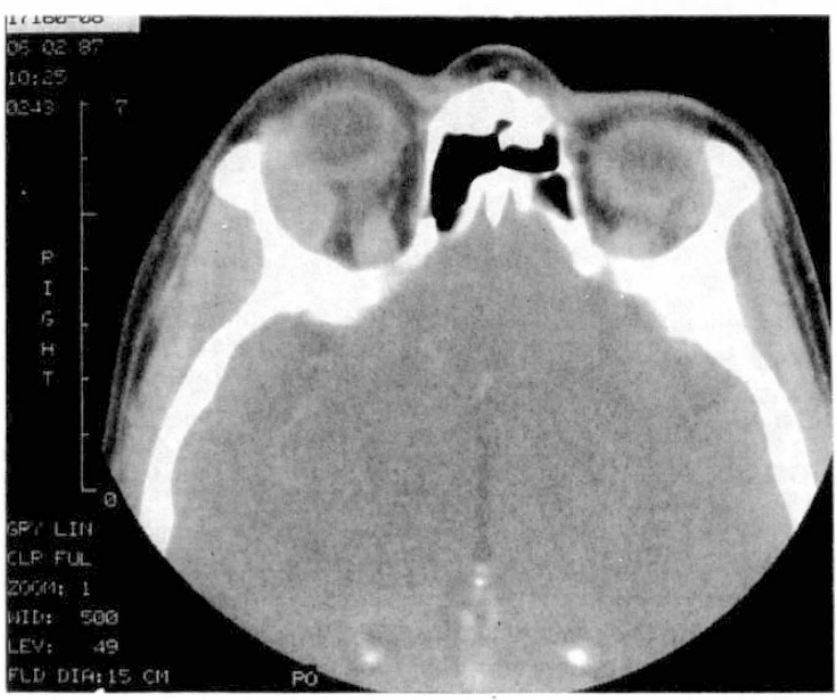

Fig. 1. Orbital Castleman's disease: CT scan appearance. 


\section{HISTOPATHOLOGY AND IMMUNOHISTOCHEMISTRY}

Sections were reviewed using haematoxylin and eosin and reticulin staining. Immunostaining was by standard peroxidase-antiperoxidase techniques using antibodies to a variety of lymphoid antigens: L26, UCHL1, $\kappa, \lambda$ and $S-100$. In the absence of fresh tissue, antibody to CD1 for histiocytosis $\mathrm{X}$ was not used.

\section{Malignant Non-Hodgkin Lymphoma}

The malignant lymphomas were all non-Hodgkin type and were classified as high-grade or low-grade using criteria based on the modified Kiel classification. ${ }^{11}$ The majority of the lymphomas were in the low-grade group and all of these were B cell tumours (Fig. 2). The classifications are given in Table II. It is important to note that 2 patients from the low-grade non-Hodgkin lymphoma group had had previous biopsies diagnosed as reactive lymphoid infiltrates.

\section{Histopathology of Castleman's Disease}

The biopsy showed a nodule of lymphoid tissue which appeared to be infiltrating or arising from the lacrimal gland. It demonstrated the characteristic features of the hyaline vascular variant $(\mathrm{HV})$ of this disease. ${ }^{12}$ Nodules of small lymphocytes were arranged in concentric rings around hyalinised vessels and between the nodules were larger lymphoid cells. Immunohistochemistry showed the nodules to be composed of B cells expressing both kappa and lambda light chains and the intervening matrix was composed of T cells (Fig. 3).

\section{DISCUSSION}

Lymphoid infiltrative lesions accounted for $27 \%$ of the diseases found in a series of 100 orbitotomies. Among these lymphomatous conditions a case of Castleman's disease was found.

\section{Aetiology of Castleman's Disease}

The apparent lymph node architecture of some of these

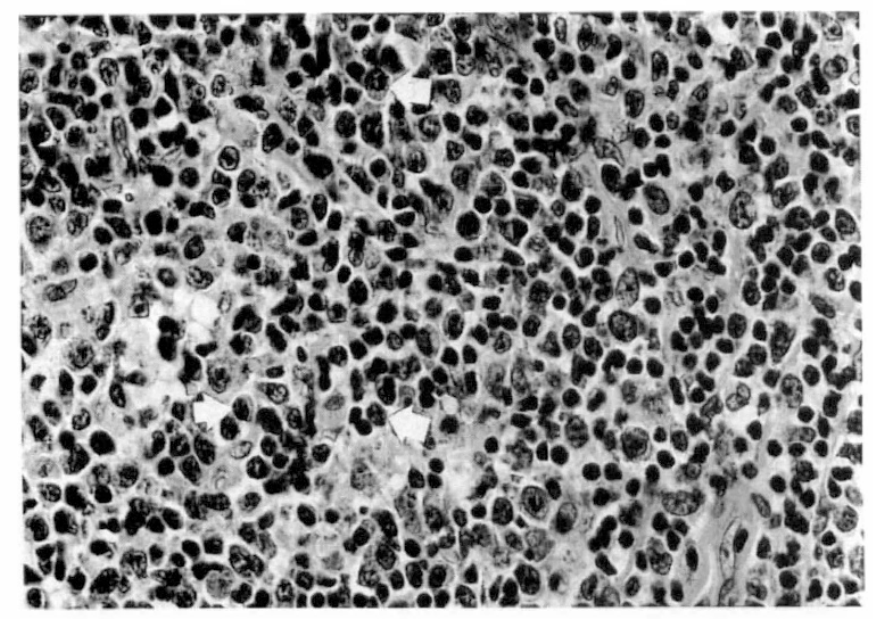

Fig. 2. Lymphoplasmacytoid non-Hodgkin lymphoma: highpower view showing the tumour consisting of small cells resembling mature lymphocytes, some of which have plasmacytoid features (arrows). tumours led Castleman et al. to propose the possibility of an unusual and exaggerated inflammatory response in a lymph node as the underlying cause. However, this lymph node architectural appearance is by no means universal and against this hypothesis are the absence of symptoms in many patients and the common finding of pathological changes in only one member of a group of nodes. For these reasons Tung $e t a l{ }^{7}$ proposed the theory of a vascular hamartoma in a lymph node causing the physical distortion of normal lymphatic tissue both of the stroma and of the follicular components. To support this hypothesis they describe 3 cases of intrathoracic involvement, each with its own distinctive arterial supply. In each case the major tumour vascular supply was derived from abundant capsular vessels. In addition they describe histological evidence of vessel proliferation. Lacombe et $_{\text {al. }}{ }^{8}$ describe a single case of intracranial involvement with Castleman's disease; as lymph nodes are not normally found within the cranial cavity this provides little support for either hypothesis.

Histological confirmation of the underlying disease is important given the excellent prognosis for these patients. This is particularly so because the gross appearance of the systemic manifestation, including massive vascular adhesions to adjacent organs, may present a picture of an inoperable neoplasm. ${ }^{7}$ The disease has been divided into two types on the basis of the histological features: the hyaline vascular variant (HV), accounting for perhaps $90 \%$ of cases, and the plasma cell variant (PC), accounting for the remaining $10 \%$. In $50 \%$ of cases the PC variant is associated with a clinical syndrome of fatigue, night sweats, raised erythrocyte sedimentation rate and bone marrow plasmacytosis, whereas only $3 \%$ of cases of the more common HV variant are associated with such features.

Weisenburger et al. ${ }^{13}$ have described a series of 16 patients with multicentric angiofollicular lymph node hyperplasia (MAFH) with similar histological appearances, 14 of the 16 patients showing similarities to the PC variant. This severe multisystem disorder may be associated with anaemia, thrombocytopenia, hepatomegaly,

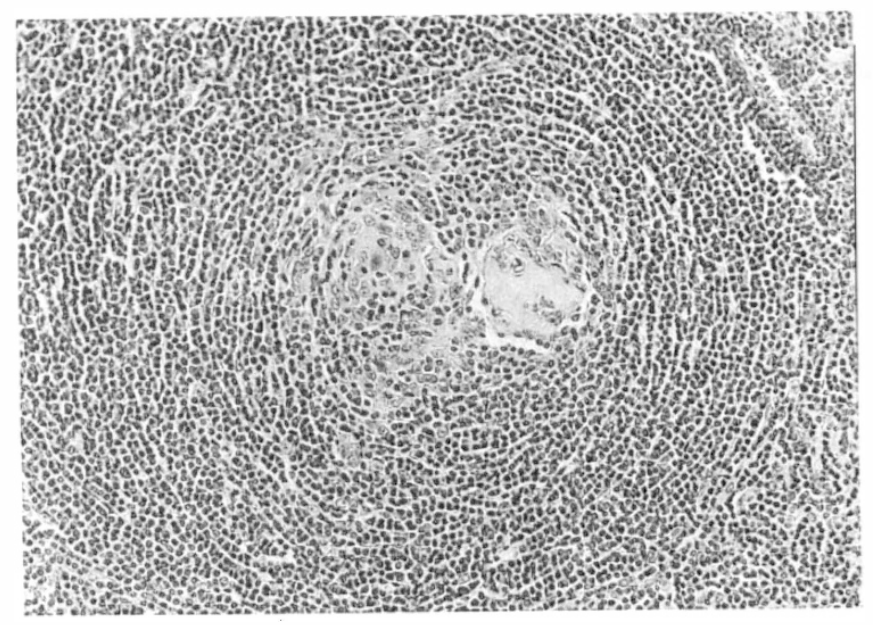

Fig. 3. Orbital Castleman's disease (HV type): high-power view showing central hyalinised vessel with concentric rings of lymphocytes (onion ringing). 
abnormal liver function tests, nephrotic syndrome and peripheral neuropathy. The authors were unable to decide whether MAFH represents a distinct entity or a variant of angiofollicular hyperplasia, and recommend that all patients presenting with angiofollicular hyperplasia should be carefully screened and monitored for multisystem disease. The histological changes in MAFH can be variable but would appear to demonstrate some preservation of the normal lymph node architecture - in contrast to the marked alteration in classic angiofollicular hyperplasia.

The case described here represents the first report of histologically proven primary orbital Castleman's disease. The gradual painless progression of symptoms would be in keeping with the general behaviour of singlesite disease at other anatomical locations but also makes the differential diagnosis from orbital lymphoma impossible on clinical grounds alone. Biopsy and histopathological examination of the characteristic features are therefore essential given the excellent prognosis for these patients following surgical excision. Whether this disease represents an inflammatory response with or without prior infection, a lymph node hamartoma or a lymphoma variant remains unknown. Lymph nodes are not found in the orbit and the case reported here lends support to the arguments of others ${ }^{8}$ against the hypothesis of lymph node hyperplasia. It is important to recognise that this disease can simulate an orbital lymphoid infiltration and surgical excision of single-site disease would appear to carry a good prognosis. Also the patient needs to be screened for multicentric disease which may require treatment with radiotherapy.

The other cases in this series include both primary and secondary lymphoid infiltrations of the orbit. In the majority (23/26) the orbit was the site of primary disease. Knowles and Jakobiec ${ }^{14}$ note that the natural histories of orbital and conjunctival lymphoid lesions differ significantly, and postulate that this is because the conjunctiva has indigenous lymphoid tissue whereas the orbit proper does not. ${ }^{15}$ They argue that this may be the reason why benign conjunctival lymphoid lesions outnumber malignant lymphoid lesions by a ratio of about 5:1 in their series whereas with pure orbital lymphoid infiltrations the reverse is true (malignant lesions outnumbering benign by $2: 1)$.

The cases studied would support this contention and for this reason all conjunctival lymphoid lesions were excluded from this series - which therefore differs from many previously reported series. ${ }^{16-19}$ The ratio of malignant to benign lesions in this series was almost $3: 1$.

Many immunohistochemical stains need to be used for diagnosis and therefore it is essential to perform biopsy to obtain fresh unfixed tissue. In 15 patients with malignant non-Hodgkin lymphoma excision biopsy was performed before commencement of any treatment; even so 2 patients required subsequent biopsies before the diagnosis was established. Interestingly one of these patients presented with a relatively short (4 month) history of painful proptosis and associated inflammation and lid swelling. In 2 other patients who were already receiving steroid treatment prior to their biopsy the initial biopsy was inconclusive and the diagnosis of malignant non-Hodgkin lymphoma was confirmed at subsequent biopsy. Knowles and Jakobiec ${ }^{20}$ found that $15 \%$ of their pseudotumour group developed systemic malignant non-Hodgkin lymphoma and Tosi et al.$^{18}$ reported a similar finding in $15.8 \%$ of their pseudotumour series showing confirmed nonHodgkin lymphoma after a mean interval of 16.6 months. Almost any infiltrative lesion will shrink to some degree initially with steroid therapy and there is evidence of lymphoblastic lymphoma undergoing lysis following intravenous methylprednisolone treatment for anaphylaxis. ${ }^{21}$ This raises the possibility of systemic steroid affecting the histological interpretation of lymphoid lesions.

In view of this and the difficulty in differentiatimg on clinical grounds alone between benign and malignant lesions, we would not support a trial of steroid treatment prior to biopsy in cases of suspected pseudotumour. The results given here demonstrate that although some features are suggestive, there is no reliable way of distinguishing benign from malignant disease on clinical grounds alone. Radiological differential diagnosis is also unreliable. ${ }^{22}$

\section{CONCLUSIONS}

A new form of primary lymphoid infiltration and its complete resolution following surgical excision is described. Histological examination with fresh unfixed tissue available for immunohistochemical staining enhances the diagnostic accuracy of these varied underlying diseases. More than one biopsy may be required before the diagnosis is established. These are significant factors given the differing lines of management for each disorder.

Key words: Angiofollicular lymphoid hyperplasia, Castleman's disease, Lymphoma, Orbital lymphoid infiltration.

\section{REFERENCES}

1. Tewfik HH, Platz CE, et al. A clinicopathological study of orbital and adnexal non-Hodgkin lymphoma. Cancer 1979; 44:1022-8.

2. Castleman B, et al. Case 40011 (hyperplasia of mediastinal lymph nodes). N Engl J Med 1954;250:26-30.

3. Castleman B, Iverson L, et al. Localised mediastinal lymph node hyperplasia resembling thymoma. Cancer 1956;9: 823-30.

4. Abell MR. Lymph nodal hamartoma versus thymic choristoma of the pulmonary hilum. AMA Arch Pathol 1957;64: 584-8.

5. Cohen H. Tumour-like proliferations of lymphoid tissue: occurrence in the deltoid muscle and mediastinum. J Mount Sinai Hosp 1957;24:750-60.

6. Zettergren L. Probably neoplastic proliferation of lymphoid tissue (follicular lympho-reticuloma). Acta Pathol Microbiol Scand 1961;51:113-26.

7. Tung KSK, McCormack LJ. Angiomatous lymphoid hyperplasia. Cancer 1967;20:525-36.

8. Lacombe MJ, Poirier J, et al. Intracranial lesion resembling giant lymph node hyperplasia. Am J Clin Pathol 1983;80: 721-3.

9. Gittinger JW. Ocular involvement in Castleman's disease. Ophthalmology 1989;96:1646-9. 
10. Carbone PP, Kaplan HS, et al. Report of the committee on Hodgkin's disease staging classification. Cancer Res 1971; 31:1860-1.

11. Lennert K, Mohri N, et al. Malignant lymphomas other than Hodgkin's disease. Berlin: Springer-Verlag, 1978.

12. Keller AR, Hochholzer L, et al. Hyaline vascular and plasma cell types of giant lymph node hyperplasia of the mediastinum and other locations. Cancer 1972;29:670-83.

'13. Weisenberger DD, Nathwani BN, et al. Multicentric angiofollicular lymph node hyperplasia. Hum Pathol 1985;16: $162-72$.

14. Knowles DM, Jakobiec FA. Ocular adnexal lymphoid neoplasms. Hum Pathol 1982;13:148-61.

15. Jakobiec FA, Iwamoto T. The ocular adnexae. In: Fine B, Yanoff M, editors. Ocular histology. Hagerstown, Md: Harper \& Row, 1979:289-342.

16. Vogiatziz KV. Lymphoid tumours of the orbit and ocular adnexae: a long term follow up. Ann Ophthalmol 1984;16: 1046-55.

17. Bessell EM, Henk JM, et al. Orbital and conjunctival lymphoma and treatment and prognosis. Radiother Oncol 1988; 13:237-44.

18. Tosi P, Frezzotti R, et al. Orbital lymphoid neoplasms. Orbit 1984;3:97-110.

19. Morgan G, Harry J. Lymphocytic tumours of indeterminate nature: a 5 year follow up of 98 conjunctival and orbital lesions. Br J Ophthalmol 1978;62:381-3.

20. Knowles DM, Jakobiec FA. Orbital lymphoid neoplasms: a study of 60 patients. Cancer 1972;29:670-83.

21. Smith T. Tumour lysis syndrome after steroid therapy for anaphylaxis. South Med J 1988;81:415-6.

22. Westacott S, Garner A, et al. Orbital lymphoma versus reactive lymphoid hyperplasia: an analysis of the use of computed tomography in differential diagnosis. Br J Ophthalmol 1991;75:722-5. 